\title{
Studies on postoperative neurological complications, particularly cognitive dysfunction
}

\author{
Shigeru Saito
}

Received: 15 June 2013/Accepted: 8 July 2013/Published online: 20 July 2013

(C) Japanese Society of Anesthesiologists 2013

Keywords Postoperative cognitive dysfunction Postoperative cognitive decline - Neurological complication $\cdot$ Stroke $\cdot$ Cardiopulmonary bypass

Postoperative respiratory and circulatory complications are increasingly successfully managed by advanced medical technologies. However, prevention of central nervous system (CNS) complications is not as successful. This trend seems to be more apparent in developed countries, where most patients undergoing surgeries are elderly people with coexisting diseases. For example, neuropsychological dysfunction after cardiopulmonary bypass (CPB) has been reported in more than half of patients during the early postoperative period [1]. Many original reports and review articles regarding this topic have been published in this journal. In particular, cognitive dysfunctions following cardiac and orthopedic surgery are often discussed.

Cerebral infarction can be fatal or can cause severe disabilities. Hence, this complication is the most serious central neurological complication after surgery. Fortunately, however, the incidence of severe cases is not very high, the overall stroke rate in an analysis of large cohorts reportedly being approximately $1-2 \%[1,2]$. However, the incidence of minor neurological complications following major surgeries is quite high, with cognitive dysfunction being far more common than stroke [2]. Although these are categorized as "clinically minor complications," they are

S. Saito $(\square)$

Department of Anesthesiology, Gunma University Graduate

School of Medicine, 3-39-22 Showa-machi,

Maebashi 371-8511, Japan

e-mail: shigerus@showa.gunma-u.ac.jp capable of interfering with the life of patients postoperatively.

There is wide variation among the reported rate of cognitive dysfunction after major surgery $[1,2]$. In the immediate postoperative period, the incidence ranges as high as $80-90 \%$, which means that almost all patients experience cognitive abnormalities after major surgery. However, at several months after the surgery, the incidence decreases to less than half of the patients, further decreasing to around one-fourth of patients at 1 year after the surgery. Although it may be true that most of the early cognitive loss is transient, multiple longitudinal studies demonstrated that, in some cases, it persists for several years after surgery, especially after cardiac surgery [3]. The incidence of long-lasting neurological symptoms seems not to be negligible. Minor neurological injuries, such as cognitive dysfunctions, do not necessarily increase the number of bedridden patients as seen after stroke. However, the extremely high incidence compared to stroke makes these injuries extremely problematic, in terms of the social impact, such as quality of life of an aged population and economic burden on healthcare resources.

Among the various postoperative cognitive dysfunctions, postoperative cognitive decline (POCD) represents trivial cognitive dysfunction [2]. After a surgical procedure, patients frequently complain of memory loss and lack of concentration. Symptoms of such subtle cognitive abnormalities experienced after an operation are described as POCD. Although minor symptoms are not noticeable to other people, the patients themselves can sense the apparent abnormalities. Minor cognitive dysfunction itself is not life threatening, and the subtle differences in cognitive performance are extremely difficult to measure. For this reason, the true prevalence of POCD is uncertain. 
As an unignorable fact for anesthesiologists, patients often attribute these symptoms to intraoperative anesthesia management [2]. However, there is little evidence that POCD is caused by anesthesia management, including general anesthesia. Several clinical studies demonstrated that the anesthetic technique is not a determinant of POCD $[2,4]$. Furthermore, the risk of POCD is reported to be similar after both general and regional anesthesia.

There are many reports describing the relationship between the type of operation and the incidence of neurological complications. Postoperative cognitive dysfunctions, which are apparent even without neuropsychological testing, are reported most frequently after cardiac and hip replacement surgery [5-7]. This trend is consistent among clinical reports. In these cases, neurological dysfunction probably reflects microembolic brain injury. The incidence after thoracic surgery and abdominal surgery has also been reported in this journal $[8,9]$.

Apart from the nature of the surgical procedure, advanced age is another important risk factor for postoperative cognitive dysfunction [1,2]. Although cognitive dysfunction is also seen in pediatric cases after surgeries, those dysfunctions seen in younger children should not be considered together with geriatric cases [10]. Developing and mature brains behave differently when faced with clinical insults. Because advances in surgical technologies have allowed invasive surgeries to be performed on a progressively older and sicker population, these older and/ or sicker populations are considered to be at particular risk for cerebral injury during surgery [11].

Along with the effect of aging, coexisting diseases and preoperative conditions have a significant impact on postoperative neurological functions. Preexisting neurological disorders and depressive tendencies have been reported to correlate with postoperative cognitive dysfunction $[12,13]$. Diabetes has been repeatedly discussed in this journal as a common preoperative disorder that is related to postoperative condition $[13,14]$. It is widely known that the presence of diabetes mellitus is a risk factor for stroke and cognitive dysfunction after cardiac surgery [5, 11]. One possible mechanism for the more frequent occurrence of postoperative cognitive changes in diabetic patients is reportedly their abnormal cerebral autoregulation during cardiopulmonary bypass [14]. Reduced cerebrovascular $\mathrm{CO}_{2}$ reactivity in diabetic patients might be one of the risk factors for postoperative cognitive dysfunction after coronary artery bypass graft surgery. Metabolic syndrome, which is considered to be a precursor of several lifestylerelated diseases, such as diabetes, hypertension, and coronary artery diseases, is also reported to be a risk factor for postoperative cognitive dysfunction [15].

Several recent original articles in this journal have discussed the various mechanisms of postoperative cognitive dysfunctions. As mentioned earlier, embolization of particulate and gaseous material into the cerebral microvasculature, resulting in focal areas of cerebral ischemia, has been best studied, especially in cardiac and orthopedic cases [2,3]. These etiologies propose ischemia and its sequelae to be important pathophysiological events. However, clinical and experimental data have also proposed other mechanisms for cognitive dysfunction. For example, cerebral as well as systemic inflammatory effects can be induced during cardiopulmonary bypass, leading to injury, both directly and indirectly, to brain cells [16]. In addition, cerebral edema documented by postoperative magnetic resonance imaging (MRI) has also been demonstrated in patients undergoing gastrointestinal surgeries [17]. A hyperthermic response occurs in the early postoperative period following cardiac surgery, which has been linked to cognitive decline 6 weeks after cardiac surgery [3]. Several biomarkers have also been proposed as being effective in predicting and diagnosing postoperative neurological sequelae $[6,7]$. Furthermore, although there is no solid scientific evidence for this, genetic variations, such as apolipoprotein genotype, have been reported to affect both the susceptibility to injury as well as the ability to recover following injury $[18,19]$. Considering that there are numerous descriptions regarding the genetic and epigenetic etiologies of neurological and circulatory disorders, it is not surprising that postoperative cognitive dysfunction has also been linked to a genetic background.

Compared to epidemiological and etiological descriptions, studies on the treatment of postoperative cognitive dysfunctions are very limited. However, the effects of aminophylline on cognitive recovery after general anesthesia were reported in a 2011 issue of this journal [20]. Although the article only discussed immediate postoperative symptoms, further studies with a similar approach could help tackle this widely observed clinical problem.

Newman et al. [21] reported that deteriorated cognitive function was observed in more than half of patients after cardiac surgery in their 5-year follow up, and that the lower cognitive function scores were associated with poorer general health and a less productive working status. Inouye et al. estimated that each year cognitive impairment complicates hospital stays for more than 2.3 million older people, involves more than 17.5 million inpatient days, and accounts for more than $\$ 4$ billion of Medicare expenditures in the United States. Substantial additional costs accrue after discharge from the hospital, because of the increased need for institutionalization, rehabilitation, and home care [22]. Physicians' attention must go into improvement in brain protection and quality of life. A multidisciplinary approach must be developed to minimize the adverse affects of operation on cognitive function because deterioration in cognitive function has adverse societal consequences. 


\section{References}

1. Newman MF, Kirchner JL, Phillips-Bute B, Gaver V, Grocott H, Jones RH, Mark DB, Reves JG, Blumenthal JA. Longitudinal assessment of neurocognitive function after coronary-artery bypass surgery. N Engl J Med. 2001;344:395-402.

2. Sauër AM, Kalkman C, van Dijk D. Postoperative cognitive decline. J Anesth. 2009;23:256-9.

3. Grocott HP, Yoshitani K. Neuroprotection during cardiac surgery. J Anesth. 2007;21:367-77.

4. Kadoi Y, Goto F. Sevoflurane anesthesia did not affect postoperative cognitive dysfunction in patients undergoing coronary artery bypass graft surgery. J Anesth. 2007;21:330-5.

5. Baba T, Goto T, Maekawa K, Ito A, Yoshitake A, Koshiji T. Early neuropsychological dysfunction in elderly high-risk patients after on-pump and off-pump coronary bypass surgery. J Anesth. 2007;21:452-8.

6. Ji MH, Yuan HM, Zhang GF, Li XM, Dong L, Li WY, Zhou ZQ, Yang JJ. Changes in plasma and cerebrospinal fluid biomarkers in aged patients with early postoperative cognitive dysfunction following total hip-replacement surgery. J Anesth. 2013;27: 236-42.

7. Ji MH, Shen JC, Gao R, Liu XY, Yuan HM, Dong L, Wu J, Feng SW, Li WY, Yang JJ. Early postoperative cognitive dysfunction is associated with higher cortisol levels in aged patients following hip fracture surgery. J Anesth. 2013 [Epub ahead of print].

8. Suehiro K, Okutai R. Duration of cerebral desaturation time during single-lung ventilation correlates with mini mental state examination score. J Anesth. 2011;25:345-9.

9. Morimoto Y, Yoshimura M, Utada K, Setoyama K, Matsumoto M, Sakabe T. Prediction of postoperative delirium after abdominal surgery in the elderly. J Anesth. 2009;23:51-6.

10. Fan Q, Cai Y, Chen K, Li W. Prognostic study of sevofluranebased general anesthesia on cognitive function in children. J Anesth. 2013. [Epub ahead of print].

11. Ito A, Goto T, Maekawa K, Baba T, Mishima Y, Ushijima K. Postoperative neurological complications and risk factors for preexisting silent brain infarction in elderly patients undergoing coronary artery bypass grafting. J Anesth. 2012;26:405-11.

12. Maekawa K, Goto T, Baba T, Yoshitake A, Katahira K, Yamamoto $\mathrm{T}$. Impaired cognition preceding cardiac surgery is related to cerebral ischemic lesions. J Anesth. 2011;25:330-6.
13. Kadoi Y, Kawauchi C, Ide M, Kuroda M, Takahashi K, Saito S, Fujita N, Mizutani A. Preoperative depression is a risk factor for postoperative short-term and long-term cognitive dysfunction in patients with diabetes mellitus. J Anesth. 2011;25:10-7.

14. Kadoi Y, Kawauchi C, Kuroda M, Takahashi K, Saito S, Fujita N, Mizutani A. Association between cerebrovascular carbon dioxide reactivity and postoperative short-term and long-term cognitive dysfunction in patients with diabetes mellitus. J Anesth. 2011;25:641-7.

15. Hudetz JA, Patterson KM, Amole O, Riley AV, Pagel PS. Postoperative cognitive dysfunction after noncardiac surgery: effects of metabolic syndrome. J Anesth. 2011;25:337-44.

16. Hudetz JA, Gandhi SD, Iqbal Z, Patterson KM, Pagel PS. Elevated postoperative inflammatory biomarkers are associated with short- and medium-term cognitive dysfunction after coronary artery surgery. J Anesth. 2011;25:1-9.

17. Chen MH, Liao Y, Rong PF, Hu R, Lin GX, Ouyang W. Hippocampal volume reduction in elderly patients at risk for postoperative cognitive dysfunction. J Anesth. 2013. [Epub ahead of print].

18. Ancelin ML, de Roquefeuil G, Scali J, Bonnel F, Adam JF, Cheminal JC, Cristol JP, Dupuy AM, Carrière I, Ritchie KJ. Long-term post-operative cognitive decline in the elderly: the effects of anesthesia type, apolipoprotein E genotype, and clinical antecedents. Alzheimers Dis. 2010;22(suppl 3):105-13.

19. Voigt Hansen M, Rasmussen LS, Jespersgaard C, Rosenberg J, Gogenur I. There is no association between the circadian clock gene HPER3 and cognitive dysfunction after noncardiac surgery. Anesth Analg. 2012;115:379-85.

20. El Tahan MR. Effects of aminophylline on cognitive recovery after sevoflurane anesthesia. J Anesth. 2011;25:648-56.

21. Newman MF, Grocott HP, Mathew JP, White WD, Landolfo K, Reves JG, Laskowitz DT, Mark DB, Blumenthal JA; Neurologic Outcome Research Group and the Cardiothoracic Anesthesia Research Endeavors (CARE) Investigators of the Duke Heart Center. Report of the substudy assessing the impact of neurocognitive function on quality of life 5 years after cardiac surgery. Stroke. 2001;32:2874-81.

22. Inouye SK, Bogardus ST, Charpentier PA, Leo-Summers L, Acampora D, Holford TR, Cooney LM. A multicomponent intervention to prevent delirium in hospitalized older patients. N Engl J Med. 1999;340:669-76. 